\title{
Mineralization and Expression of Col1a1-3.6GFP Transgene in Primary Dental Pulp Culture
}

\author{
Anamaria Balic Barbara Rodgers Mina Mina \\ Department of Craniofacial Sciences, School of Dental Medicine, University of Connecticut Health Center, \\ Farmington, Conn., USA
}

\section{Key Words}

Mineralization · Dentin - Dental pulp · Progenitors · Col1a1-3.6GFP

\begin{abstract}
We have examined and compared the effects of various differentiation-inducing media on mineralization, cell morphology and expression of pOBCol3.6GFP (3.6-GFP) in primary dental pulp cultures derived from 3.6-GFP transgenic mice. Our results show that media containing ascorbic acid only could not induce mineralization in primary dental pulp cultures. On the other hand, media containing ascorbic acid and $\beta$-glycerophosphate induced formation of mineralized matrix-containing dentin. The amount of mineralized matrix was increased by addition of dexamethasone. Cells treated with ascorbic acid and $\beta$-glycerophosphate were fibroblast like and cells treated with dexamethasone were cuboidal. In all culture conditions, high levels of 3.6-GFP were expressed in areas of mineralization

Copyright $\odot 2008$ S. Karger AG, Basel
\end{abstract}

\section{Introduction}

Dentinogenesis is regulated by a single layer of postmitotic odontoblasts originating from the neural crestderived cells of the dental papilla [Arana-Chavez and
Massa, 2004]. The cellular and molecular mechanisms regulating dentinogenesis have been the subject of intense investigation using a variety of in vitro and in vivo approaches [Tziafas et al., 2002]. Several in vitro culture systems have been developed for studies on differentiation of odontoblasts including clonal cell lines, primary cultures established from digested pulp and cell outgrowth from cultured explants [Tziafas et al., 2002]. Most often, published results are based on observations in whole primary dental pulp cultures, which are composed of a heterogeneous population of cells composed of fibroblasts, macrophages, endothelial cells and lymphocytes [Ten Cate, 1998]. In addition, differences in the stages at which cells are prepared for culture, in the methods used

\begin{tabular}{ll} 
Abbreviations used in this paper \\
\hline 3.6-GFP & pOBCol3.6GFP \\
AA & ascorbic acid \\
AR-S & alizarin red S \\
$\beta-G P$ & $\beta$-glycerophosphate \\
DEX & dexamethasone \\
Dmp1 & dentin matrix protein 1 \\
DSPP & dentin sialophosphoprotein \\
FBS & fetal bovine serum \\
PBS & phosphate-buffered saline
\end{tabular}

\section{KARGER}

(ㄷ) 2008 S. Karger AG, Basel

Fax +41613061234 E-Mail karger@karger.ch www.karger.com www.karger.com/cto
Dr. Mina Mina

Division of Pediatric Dentistry, Department of Craniofacial Sciences

University of Connecticut Health Center

263 Farmington Ave, Farmington, CT 06030 (USA)

Tel. +1 860679 4081, Fax +1 860679 4078,E-Mail mina@nsol.uchc.edu 
for examination of cell differentiation and in the methods/reagents used to induce cell differentiation make it difficult to compare the results from various in vitro studies.

We have used pOBCol3.6GFP (3.6-GFP) and pOBCol2.3GFP (2.3-GFP) transgenic animals to gain insight into stem/progenitor cells in the adult murine dental pulp [Braut et al., 2002, 2003; Mina and Braut, 2004; Balic and Mina, 2005]. Our analysis of the pattern of expression of Colla1-GFP transgenes in the developing teeth of 2.3-GFP and 3.6-GFP mice show that, in developing teeth, expression of 3.6-GFP and 2.3-GFP are well correlated with different stages of odontoblast differentiation. 3.6-GFP and 2.3-GFP are expressed at low but detectable levels at the bell stage (embryonal day 18) of tooth development. At the late bell stage of tooth development (embryonal day 19), high levels of Colla1-GFP are expressed in functional odontoblasts engaged in the secretion of a thin layer of predentin. At the secretory stage of crown formation during postnatal growth (postnatal days 1-5), high levels of Col1a1-GFP are expressed in the entire layer of odontoblasts covering the dental pulp and extend into the odontoblast processes. Comparison of the patterns of expression of Colla1-GFP with those of dentin sialophosphoprotein (DSPP) and dentin matrix protein 1 (Dmp1) show that during odontoblast differentiation, Colla1-GFP transgenes are activated prior to the expression of DSPP (specific marker for odontoblasts) [Braut et al., 2002, 2003; Mina and Braut, 2004; Balic and Mina, 2005]. Our transplantation studies [Braut et al., 2003] resulted in the characterization of multipotent cells from dental pulps that are capable of giving rise to multiple cell types including odontoblasts secreting dentin, cartilage as well as osteoblasts secreting bone-like matrices. Dentin-like matrices were composed of tubular-containing matrix lined with cells expressing high levels of 2.3-GFP and DSPP and very few if any osteocyte-like cells. On the other hand, bone-like matrices were composed of atubular-containing matrix with osteocyte-like cells embedded within the matrix expressing high levels of 2.3-GFP and Dmp1. More recently, we have initiated studies using primary cell cultures derived from the coronal portion of dental pulp from these transgenic mice [Balic and Mina, 2005]. The goal of this study was to examine and compare the effects of various differentiation-inducing media on mineralization, cell morphology and expression of 3.6-GFP in primary dental pulp cultures.

\section{Materials and Methods}

\section{Primary Pulp Cultures}

The coronal portions of the pulps from first molars of 5- to 7day-old hemizygous pOBCol3.6GFP mice was isolated and digested with an enzyme mixture containing $0.05 \%$ trypsin (Invitrogen) and $1.5 \mathrm{U} / \mathrm{ml}$ Collagenase $\mathrm{P}$ (Roche) in phosphate-buffered saline (PBS) at $37^{\circ} \mathrm{C}$ for $30 \mathrm{~min}$ on a rocking platform. A singlecell suspension was obtained by passing the cells through narrowed Pasteur pipettes and a $70-\mu \mathrm{m}$ strainer. Cells were counted using $0.4 \%$ Trypan blue and plated at $5 \times 10^{5}$ cells/well in $35-\mathrm{mm}$ culture plates. Cells were grown first in media containing Dulbecco's modified Eagles' medium (Invitrogen) containing 20\% fetal bovine serum (FBS; Hyclone), $40 \mathrm{U} / \mathrm{ml}$ penicillin and $40 \mu \mathrm{g} /$ $\mathrm{ml}$ streptomycin, $0.1 \mu \mathrm{g} / \mathrm{ml}$ Fungizone (Invitrogen) and $2 \mathrm{~mm}$ glutamine (Invitrogen) at $37^{\circ} \mathrm{C}$ and $5 \% \mathrm{CO}_{2}$. Three days later, the media were changed to media containing $10 \%$ FBS. On day 7 , when the cells reached confluence, mineralization-promoting media was added to the cultures. The differentiation media consisted of $\alpha$-MEM, $10 \%$ FBS, $50 \mu \mathrm{g} / \mathrm{ml}$ ascorbic acid (AA), and different concentration ( 4 and $8 \mathrm{mM}$ ) of $\beta$-glycerophosphate $(\beta-\mathrm{GP})$ and $10^{-8} \mathrm{M}$ dexamethasone (DEX).

Digital Imaging and Epifluorescence Analysis in Cell Culture GFP expression in cell culture was visualized using an Olympus IX50 inverted microscope equipped with an IX-FLA inverted reflected light fluorescence (Olympus America Inc.). A specific excitation wavelength was obtained using filters for GFPtpz (exciter: D500/20; dichroic: 525DCLP; emitter: D550/40). Images were captured using a SPOTcamera (Diagnostic Instruments Inc.). Phase contrast images were converted to grayscale.

Detection and Quantification of Mineralization in Cultures

The mineralization in these cultures was assayed using von Kossa and alizarin red S (AR-S) staining to examine the phosphate and calcium deposits/contents, respectively. For von Kossa staining, cells were fixed for $10 \mathrm{~min}$ in $2 \%$ paraformaldehyde in $0.1 \mathrm{M}$ sodium cacodylate, pretreated for $20 \mathrm{~min}$ with saturated lithium carbonate solution and washed with deionized water. The plates were incubated with 5\% silver nitrate solution for 2 cycles using the UV Stratalinker (Strategene). Cultures were washed with water, treated briefly with $5 \%$ sodium thiosulphate solution to remove the background, air dried and photographed.

AR-S staining and quantification were performed as previously described [Stanford et al., 1995] with minor modifications. Cultures were rinsed with PBS, fixed for $1 \mathrm{~h}$ with cold $70 \%$ ethanol, and stained for $10 \mathrm{~min}$ with $40 \mathrm{mM}$ AR-S (Allied Chemicals), $\mathrm{pH} 4.2$, at room temperature on the rotating platform. After staining, cultures were rinsed with water several times and incubated with PBS for $15 \mathrm{~min}$. Stained cultures were photographed and processed for quantification of AR-S staining. AR-S was extracted using $10 \%$ cetylpyridinium chloride in $10 \mathrm{mM}$ sodium phosphate, $\mathrm{pH} 7.0$, for $30 \mathrm{~min}$ at room temperature. The procedure was repeated several times to ensure complete extraction of the dye. Aliquots of the extracted materials were pooled and diluted with $10 \%$ cetylpyridinium chloride. The concentration of AR-S in different cultures was determined spectrophotometrically using an ELISA reader with a 562-nm filter, using an AR-S standard curve. 


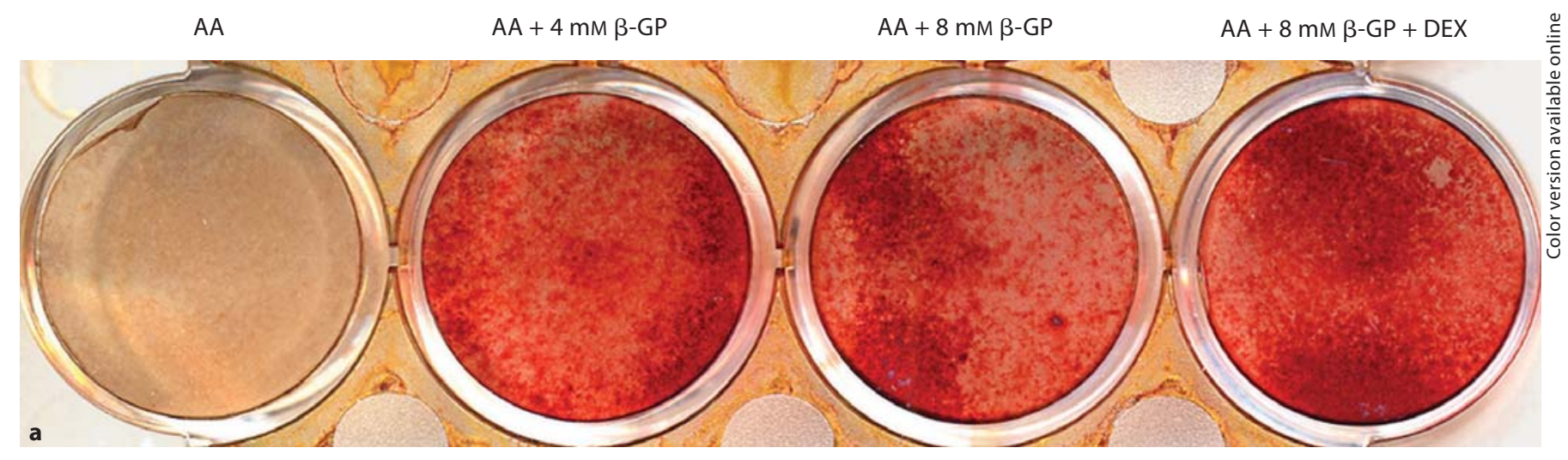

Fig. 1. Effects of various differentiation-inducing media on mineralization by dental pulp cells. a Photograph of 14-day-old AR-S-stained cultures grown in various differentiation media. Note the lack of staining in cultures grown in media containing only AA. Note the staining in cultures grown in media containing $\beta$-GP and $10^{-8} \mathrm{M}$ DEX. $\mathbf{b}$ Bar histogram showing the effects of various differentiation-inducing media on the amount of extracted AR-S. There are no significant differences in the amount of extracted AR-S between cultures grown with $4 \mathrm{~mm}$ and $8 \mathrm{~mm}$ $\beta-G P(p>0.1)$. Note the significant increase in cultures grown in the presence of $10^{-8} \mathrm{MDEX}\left({ }^{*} \mathrm{p}<0.05\right)$. Results represent the concentration of the extracted AR-S calculated from the mean absorbance \pm SE for 2 independent experiments with multiple samples (3 or more) in each experiment.

\section{Results}

Primary cultures were established from coronal portions of the pulps (first molars) from 3.6-GFP mice. Differentiation and mineralization were induced by addition of the media containing $50 \mu \mathrm{g} / \mathrm{ml} \mathrm{AA}$ and $4 \mathrm{mM} \beta$-GP at day 7 and then for the duration of the experiment $(21$ days). As the first step, we examined the effects of various differentiation-inducing media on the amount and extent of mineralization in these cultures by van Kossa and AR-S staining 7 days after addition of differentiation-inducing medium. There was no evidence of mineralization in primary pulp cultures grown in the presence of only AA (fig. 1a). On the other hand, there was extensive mineralization in cultures treated with AA and $\beta-\mathrm{GP}$ (fig. 1a). Quantitative analysis showed no significant differences in the amount of AR-S-stained matrix in cul-

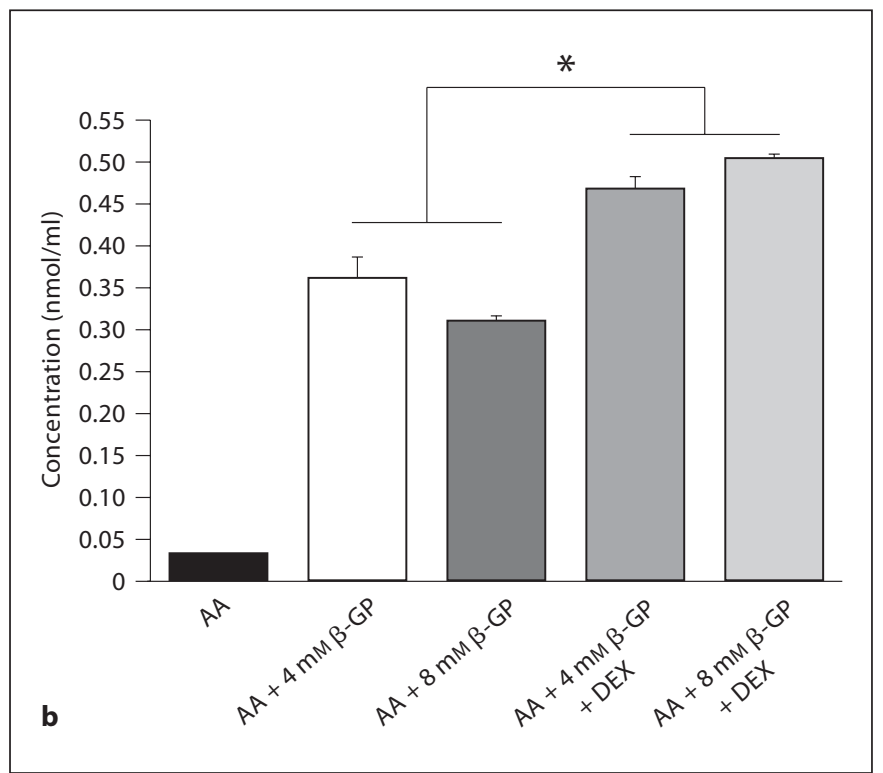

tures treated with 4 and $8 \mathrm{~mm} \beta$-GP (fig. 1b). However, addition of DEX to primary cultures resulted in significant increases in the amount and extent of mineralization compared with cultures treated with $\beta$-GP (fig. 1a, b). RT-PCR analysis showed that mineralization in these cultures was associated with increases in the expression of selected known markers of mineralization, including osteocalcin, DMP1 and DSPP (data not shown).

The differences in the amount and extent of mineralization were accompanied by differences in the cell morphology. Cultures treated with only AA contained fibroblast-like cells with short processes (fig. 2a). Mineralized nodules formed in cultures treated with AA and $\beta$-GP contained multilayered fibroblast-like cells (fig. 2b), whereas cells in mineralized nodules in cultures grown in the presence of DEX displayed cuboidal morphology (fig. 2c). 

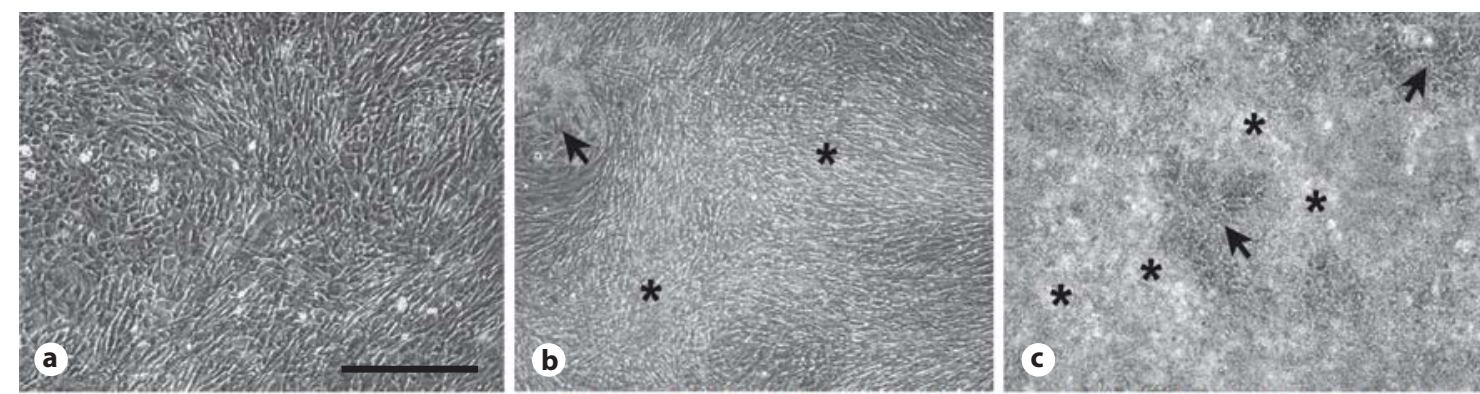

2
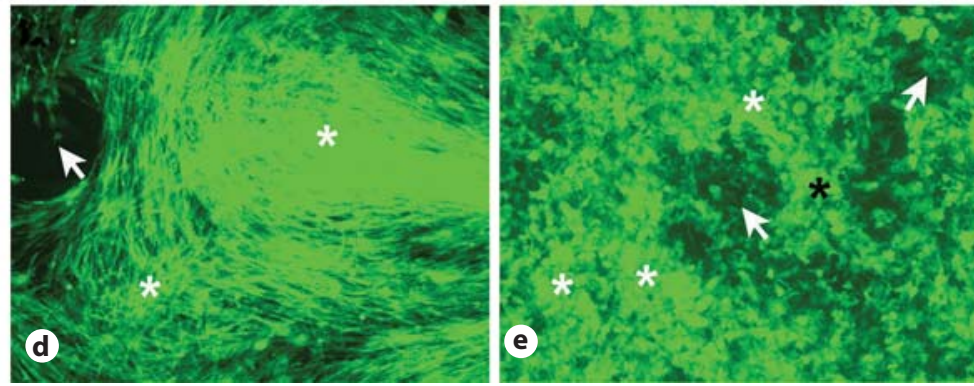

3 days
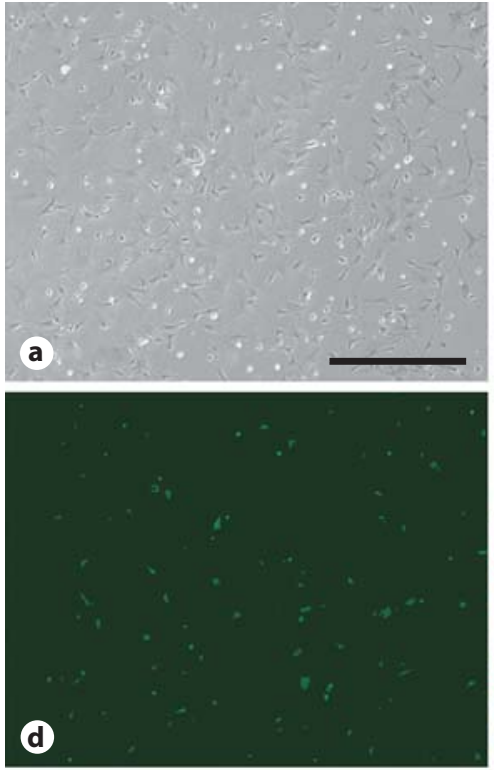

3

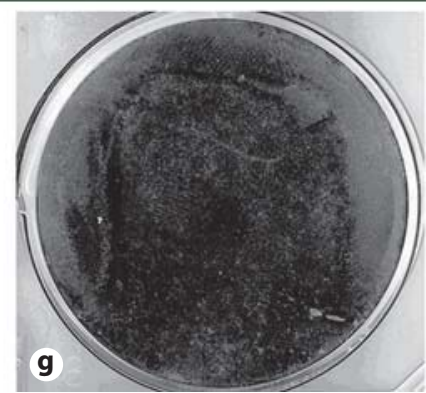

14 days
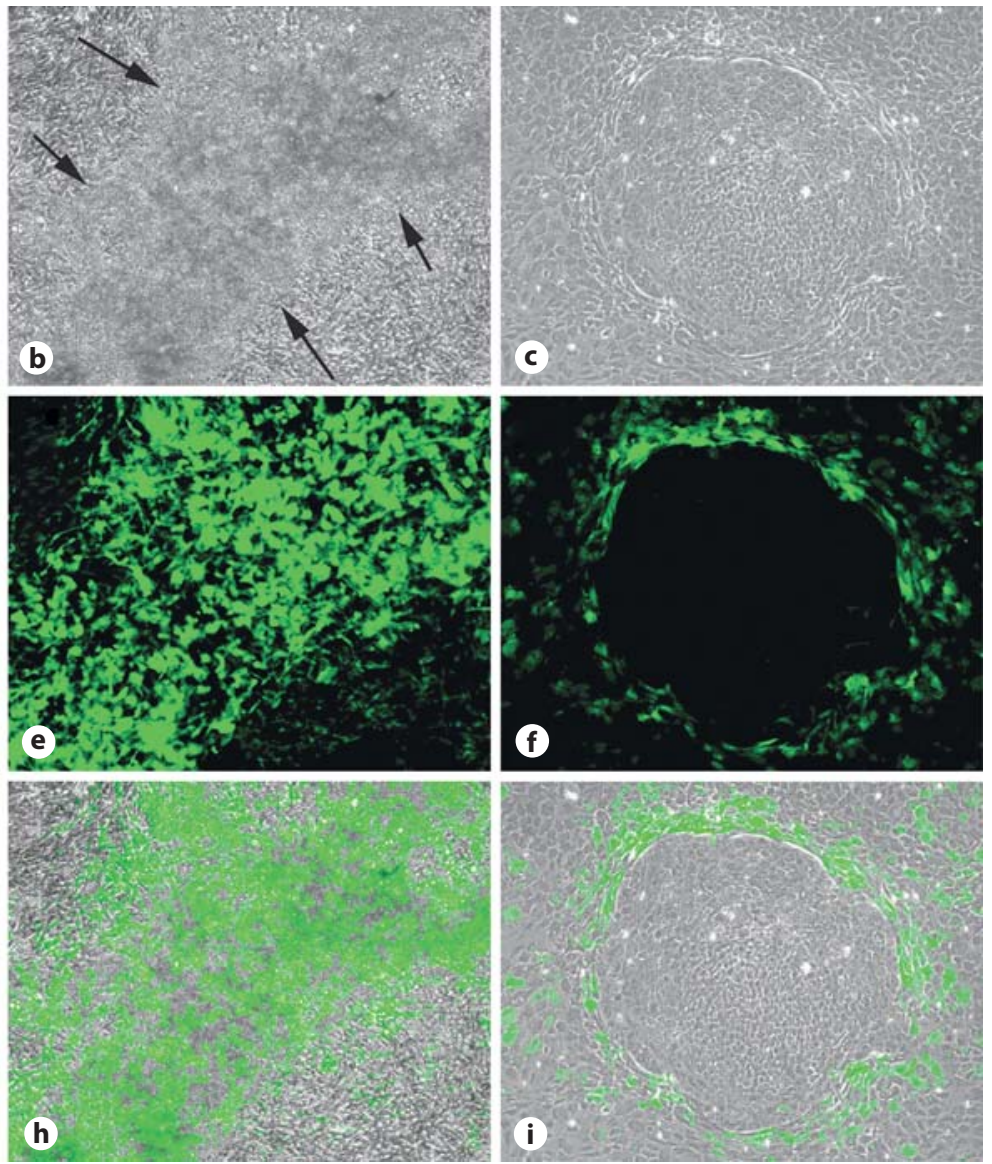
As the next step, we examined the expression of 3.6GFP in the primary culture-derived dental pulp. Expression of GFP in these cultures was also examined by inverted fluorescence microscopy using a GFP-appropriate filter. Under these conditions, weak but detectable levels of 3.6-GFP were detected in a few scattered cells at day 3 (fig. 3a, d). At day 7, elevated levels of 3.6GFP were expressed in clusters of cells and intensified in well-demarcated nodules at days 10 and 14 (fig. 3b, e, $\mathrm{h}$; data not shown). In these cultures, there was close correlation between the areas of the cultures expressing high levels 3.6-GFP and areas of mineralization (fig. 3). These cultures also contained clusters of cells that did not express 3.6-GFP but were surrounded by cells expressing 3.6-GFP (fig. 3c, f, i). Low levels of 3.6-GFP were also expressed in cells between individual nodules (fig. 3).

\section{Discussion}

In our study, we show that in primary cultures derived from the dental pulp of the 3.6-GFP transgenic mice, 3.6GFP provides an important experimental tool for the identification and isolation of cells at different stages of odontoblast differentiation. In these cultures, intense ex-

Fig. 2. Effects of various differentiation-inducing media on the cell morphology and expression of GFP. Fourteen-day-old pulp cultures established from pOBCol3.6GFP mice visualized under phase contrast and fluorescent light $(\mathbf{d}, \mathbf{e})$. In each panel, the same positions in the cultures were examined under phase contrast and epifluorescent light. Cultures treated with only AA contain fibroblast-like cells (a). Note the difference in the cell morphology in mineralized nodules (black asterisks) formed in cultures treated with $4 \mathrm{mM} \beta$-GP (b) and $10^{-8} \mathrm{M} \operatorname{DEX}(\mathbf{c})$. d, e Intense expression of 3.6-GFP in mineralized nodules is shown. Areas in the cultures that express low to no GFP are marked by arrows. White asterisks indicate cells expressing high levels of 3.6-GFP associated with mineralized nodules. Scale bar $=1 \mathrm{~mm}$.

Fig. 3. Expression of 3.6-GFP in differentiating primary dental pulp. In each panel, the same positions in the cultures were examined under phase contrast and epifluorescent light (d-f). $\mathbf{h}, \mathbf{i}$ Overlay of the phase contrast and epifluorescent images. Weak but detectable level of 3.6-GFP is expressed in scattered cells at day 3 (a, d). 3.6-GFP is expressed in mineralized nodules (b, e, $\mathbf{h})$ at day 14 . Arrows in b outline the mineralized nodules at day 14. c, f, i Representatives of clusters of cells devoid of GFP-expressing cells at day 14. Note the expression of 3.6-GFP in the surrounding cells. g Van Kossa staining of a 21-day culture showing the extensive mineralization of dental pulp cells in vitro. Scale bar $=1 \mathrm{~mm}$. pression of 3.6-GFP is seen in mineralized nodules containing dentin.

$\mathrm{AA}$, in combination with $\beta-\mathrm{GP}$ and DEX, has been used to induce in vitro mineralization of various cells, including bone marrow stromal cells [Herbertson and Aubin, 1995] as well as cultured murine dental pulp cells [Kasugai et al., 1993; Yokose et al., 2000; Yang et al., 2007; Yasuhara et al., 2007]. Our study showed that addition of $50 \mu \mathrm{g} / \mathrm{ml}$ AA alone to the primary cultures derived from dental pulp did not support in vitro mineralization, which is consistent with previous observations on the cultured calvarial osteoblasts [Bellows et al., 1986; Bonewald et al., 2003] and rat dental pulp-derived cell line M2H4 cells [Ritchie et al., 2002]. AA increases hydroxylation of procollagen, resulting in the formation of stable collagen triple helix [Franceschi, 1992; Franceschi et al., 1994]. Treatment of fibroblasts and osteoblast cell lines (MC3T3-E1) with AA increased the expression of pro $\alpha 1$ (I) collagen and collagen type I mRNA and protein, but did not support mineralization [Franceschi et al., 1994; Phillips et al., 1994; Chung et al., 1997].

$\beta-G P$ is an organic phosphate that serves as a source of inorganic phosphate after its hydrolysis by alkaline phosphatase [Chung et al., 1992]. It plays an essential role on in vitro mineralization of various cells including osteoblasts and cultured dental pulp cells [Chung et al., 1992; Kasugai et al., 1993; About et al., 2000; Yokose et al., 2000; Yasuhara et al., 2007]. We also show that $\beta-G P$ is essential for mineralization of primary cultures derived from dental pulp in vitro that is consistent with previous observations in murine dental pulp [Kasugai et al., 1993; About et al., 2000; Yokose et al., 2000; Yasuhara et al., 2007]. Our results show that $4 \mathrm{mM} \beta-\mathrm{GP}$ is sufficient for induction of mineralization and that there are no significant differences in the amount and extent of mineralization in cultures grown in the presence of 4 and $8 \mathrm{mM}$ $\beta-G P$.

DEX is a synthetic glucocorticoid that together with AA and $\beta$-GP stimulates proliferation and osteoblast differentiation of rat bone marrow stromal cells in vitro [Herbertson and Aubin, 1995]. Addition of DEX to cultured fetal rat calvarial cells induces adipogenesis and, thus, DEX is rarely used for the induction of mineralization in the calvarial cultures [Bellows et al., 1994]. Recent studies showed the negative and positive effects of DEX on proliferation and differentiation of human dental pulp cells [Alliot-Licht et al., 2005].

Our observations also show increase in the amount and extent of mineralization in primary cultures derived from dental pulp after addition of $10^{-8} \mathrm{M}$ DEX that is con- 
sistent with results reported by others [Kasugai et al., 1993; About et al., 2000; Alliot-Licht et al., 2005; Yasuhara et al., 2007]. DEX also changed the morphology of the cultured cell within mineralized nodules from elongated to cuboidal shape.

\section{Acknowledgements}

We thank all individuals providing reagents as well as Drs. John R. Harrison and Maobin Yang for their assistance in the quantification of AR-S staining. This work was supported by NIH grant R01 DE016689.

\section{References}

About, I., M.J. Bottero, P. de Denato, J. Camps, J.C. Franquin, T.A. Mitsiadis (2000) Human dentin production in vitro. Exp Cell Res 258: 33-41.

Alliot-Licht, B., G. Bluteau, D. Magne, S. LopezCazaux, B. Lieubeau, G. Daculsi, J. Guicheux (2005) Dexamethasone stimulates differentiation of odontoblast-like cells in human dental pulp cultures. Cell Tissue Res 321: 391-400.

-Arana-Chavez, V.E., L.F. Massa (2004) Odontoblasts: the cells forming and maintaining dentine. Int J Biochem Cell Biol 36: 13671373.

Balic, A., M. Mina (2005). Analysis of developmental potentials of dental pulp in vitro using GFP transgenes. Orthod Craniofac Res 8: 252-258.

Bellows, C.G., J.E. Aubin, J.N. Heersche, M.E. Antosz (1986) Mineralized bone nodules formed in vitro from enzymatically released rat calvaria cell populations. Calcif Tissue Int 38: 143-154.

Bellows, C.G., Y.H. Wang, J.N. Heersche, J.E. Aubin (1994) 1,25-dihydroxyvitamin D3 stimulates adipocyte differentiation in cultures of fetal rat calvaria cells: comparison with the effects of dexamethasone. Endocrinology 134: 2221-2229.

Bonewald, L.F., S.E. Harris, J. Rosser, M.R. Dallas, S.L. Dallas, N.P. Camacho, B. Boyan, A. Boskey (2003) von Kossa staining alone is not sufficient to confirm that mineralization in vitro represents bone formation. Calcif Tissue Int 72: 537-547.
Braut, A., I. Kalajzic, Z. Kalajzic, D.W. Rowe, E. J. Kollar, M. Mina (2002) Colla1-GFP transgene expression in developing incisors. Connect Tissue Res 43: 216-219.

Braut, A., E.J. Kollar, M. Mina (2003) Analysis of the odontogenic and osteogenic potentials of dental pulp in vivo using a colla1-2.3-GFP transgene. Int J Dev Biol 47: 281-292.

Chung, C.H., E.E. Golub, E. Forbes, T. Tokuoka, I.M. Shapiro (1992) Mechanism of action of $\beta$-glycerophosphate on bone cell mineralization. Calcif Tissue Int 51: 305-311.

Franceschi, R.T. (1992) The role of ascorbic acid in mesenchymal differentiation. Nutr Rev 50: $65-70$.

Franceschi, R.T., B.S. Iyer, Y. Cui (1994) Effects of ascorbic acid on collagen matrix formation and osteoblast differentiation in murine MC3T3-E1 cells. J Bone Miner Res 9: $843-$ 854.

Herbertson, A., J.E. Aubin (1995) Dexamethasone alters the subpopulation make-up of rat bone marrow stromal cell cultures. J Bone Miner Res 10: 285-294.

Kasugai, S., S. Shibata, S. Suzuki, T. Susami, H. Ogura (1993) Characterization of a system of mineralized-tissue formation by rat dental pulp cells in culture. Arch Oral Biol 38: 769777.

Mina, M., A. Braut (2004) New insight into progenitor/stem cells in dental pulp using Colla1-GFP transgenes. Cells Tissues Organs 176: 120-133.

Phillips, C.L., S.B. Combs, S.R. Pinnell (1994) Effects of ascorbic acid on proliferation and collagen synthesis in relation to the donor age of human dermal fibroblasts. J Invest Dermatol 103: 228-232.
Ritchie, H.H., J. Liu, S. Kasugai, P. Moller (2002) A mineralizing rat dental pulp cell subline expressing collagen type I and dentin sialoprotein-phosphophoryn transcripts. In Vitro Cell Dev Biol Anim 38: 25-29.

Stanford, C.M., P.A. Jacobson, E.D. Eanes, L.A. Lembke, R.J. Midura (1995) Rapidly forming apatitic mineral in an osteoblastic cell line (UMR 106-01 BSP). J Biol Chem 270: $9420-$ 9428.

Ten Cate, A. (1998) Dentine-pulp complex; in Ten Cate, A. (ed): Oral Histology, Development, Structure, and Function. St. Louis, Mosby, pp 169-217.

-Tziafas, D., M. Kalyva, S. Papadimitriou (2002) Experimental dentin-based approaches to tissue regeneration in vital pulp therapy. Connect Tissue Res 43: 391-395.

Yang, X., J.van den Dolder, X.F. Walboomers, W. Zhang, Z. Bian, M. Fan, J.A. Jansen (2007) The odontogenic potential of STRO-1 sorted rat dental pulp stem cells in vitro. J Tissue Eng Regen Med 1: 66-73.

- Yasuhara, R., T. Suzawa, Y. Miyamoto, X. Wang, M. Takami, A. Yamada, R. Kamijo (2007) Nitric oxide in pulp cell growth, differentiation, and mineralization. J Dent Res 86: 163168.

Yokose, S., H. Kadokura, Y. Tajima, K. Fujieda, I. Katayama, T. Matsuoka, T. Katayama (2000) Establishment and characterization of a culture system for enzymatically released rat dental pulp cells. Calcif Tissue Int 66: 139144. 